\title{
Method of stenting the lacrimal sac after performing dacryocystorhinostomy
}

\author{
Lucian Lapusneanu', Alina Neacsu \\ ${ }^{1}$ ENT Department, Braila County Emergency Hospital, Braila, Romania \\ ${ }^{2}$ Ophthalmology Department, Braila County Emergency Hospital, Braila, Romania
}

\begin{abstract}
Lacrimal stents were used in the past to preserve the caliber of the lacrimal pathways after surgery, trauma, reconstruction, etc. Recently, their role in preventing functional epiphora has also been highlighted. Over the years, the stents have evolved and different models, materials and surgical techniques for positioning have appeared. Extensive and accurate knowledge of the type and design of the stent, the correct insertion technique offer optimal results depending on the anatomical area and the type of disorder of the lacrimal pathways. We will present the advantages of a simple catheterization technique for the lacrimal sac, endoscopic post-dacryocystorhinostomy.
\end{abstract}

KEYWORDS: stent, dacryocystitis, dacryocystorhinostomy.

\section{INTRODUCTION}

This article aims to describe an alternative to bicanalicular stenting of the lacrimal sac, which I personally designed, in order to keep nasolacrimal communication patent after performing endoscopic dacryocystorhinostomy.

This method could be used in particular situations, such as: repeated dacryocystorhinostomy surgery, the young age of the patient, small or fibrous lacrimal sac, accidental damage to the sac during surgery, high deviation of the nasal septum, inadequate mucosal flaps made after intranasal marsupialization of the lacrimal sac, a history of acute dacryocystitis, in certain systemic disorders (e.g. Wegener granulomatosis) and in case of local inflammatory side effects after other types of stenting.

\section{MATERIAL AND METHODS}

In order to apply the actual technique, we selected 3 cases (women patients aged between 37 and 48 years), who had chronic dacryocystitis with multiple episodes of re-exacerbation. The patients had been treated repeatedly by the ophthalmologist with antibiotics and anti-inflammatory drugs administered orally or intravenously, but also local treatments with the attempt of catheterization of the lacrimal pathways and the use of antibiotic and anti-inflammatory eye drops. Another particular feature was that these cases had a high deviation of nasal septum on the side of the affected eye.

As appropriate, a CT or MRI examination was performed, which revealed the cystic lesion of the lacrimal sac. The ophthalmologist verified the permeability of the canaliculi (superior, inferior and common), performing the Jones fluorescein test.

The actual surgical technique was performed under general anesthesia and endoscopic control. In the first stage of the intervention, after the "L-shaped" incision of the septal mucosa, the high deviated part of the nasal septum was excised to have an easy approach of the inflamed lacrimal sac. Subsequently, we performed endoscopic dacryocystorhinostomy with the intranasal opening of the lacrimal sac (Figure 1).

The main surgical instruments used consisted of the $0^{\circ}$ optics, Kerrison rongeur, Strucken forceps, diamond drill, "sickle-shaped" scalpel, Brünings forceps, Freer elevator.

Corresponding author: Lucian Lapusneanu, MD, Address: ENT Department, Braila County Emergency Hospital, 2 Buzaului Street, 810325, Braila, Romania e-mail: llapusneanu@gmail.com

Received for publication: January 1, 2019 / Accepted: March 2, 2019 


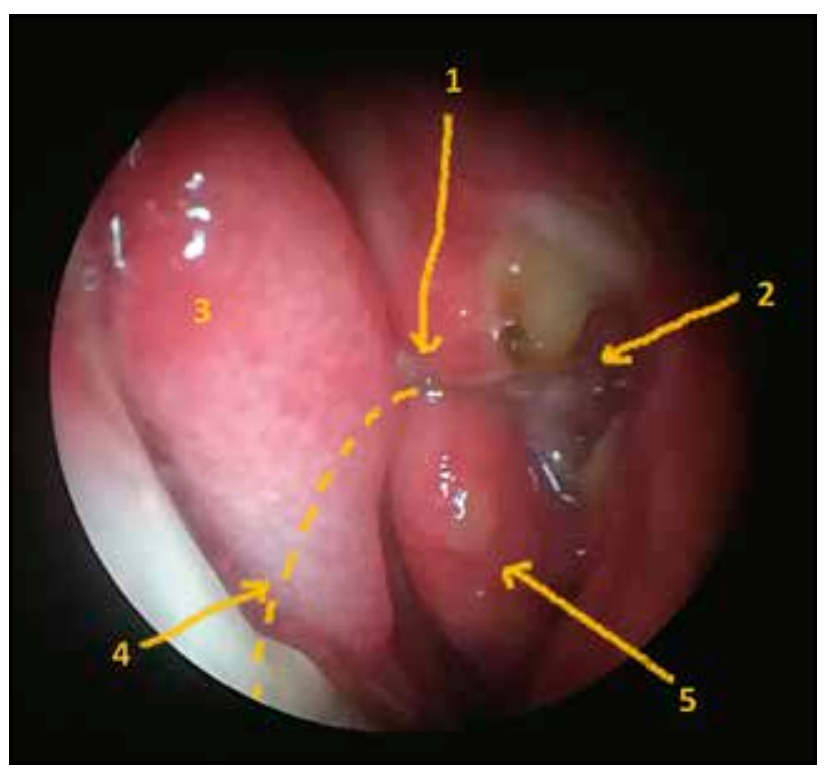

Figure 1 The lacrimal sac opened intranasally, with the stent positioned at this level and fixed under the septal mucosa flap (the catheter trajectory represented by the dotted line): $\mathbf{1}$. Catheter; $\mathbf{2}$. Lacrimal sac; $\mathbf{3}$. Septal mucosa flap; 4 . Catheter trajectory; 5 . Middle nasal turbinate.

The personal contribution and idea was that in all three cases we performed the retrograde stenting of the lacrimal sac, intranasally marsupialized, by fixing a $19 / 20 \mathrm{G}$ venous catheter (central venous catheter type), with one end at this level and the other exteriorized into the nasal cavity and fixed to the columella (Figure 2, Figure 3). The catheter was maintained between 14 and 25 days.

I mention that, in order to obtain a stable fixation, the middle part of the catheter was passed under the "Lshaped" flap made during the resection of the deviated nasal septum, being kept as in a "sandwich" between the two membranes of the septal mucosa (Figure 3). This flap was made for two reasons. First of all, it helped me to resect the high deviation of the nasal septum, thus widening the intranasal approach route of the lacrimal sac; secondly, it helped me to firmly fix the catheter by passing it under the lower portion of the flap (Figure 3).

In addition, to maintain a high degree of stability, I bent and passed the catheter under the middle turbinate and I fixed the ensemble with a Merocel swab that I suppressed after 3 days. During this time, and subsequently, fibrinous adhesions have been created, which have maintained the catheter at this level without any problem. Submucosal tunnelling allows for long-term fixation, at least 14 days, of the catheter in this position. There have been no local side effects.

The additional benefits of the method are:

- the venous catheters used for stenting may be of the central type, made of polyurethane (a biocompatible and flexible material - essential properties for a favourable postoperative evolution).

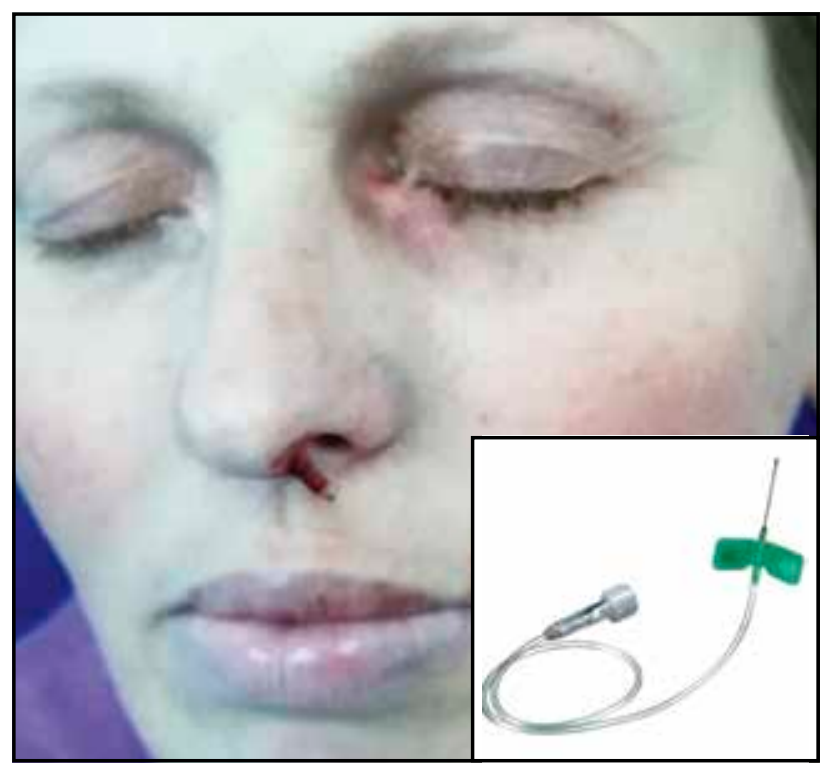

Figure 2 Nasolacrimal catheter fixed to the columella. 19G venous catheter used for stenting the lacrimal sac opened intranasally.

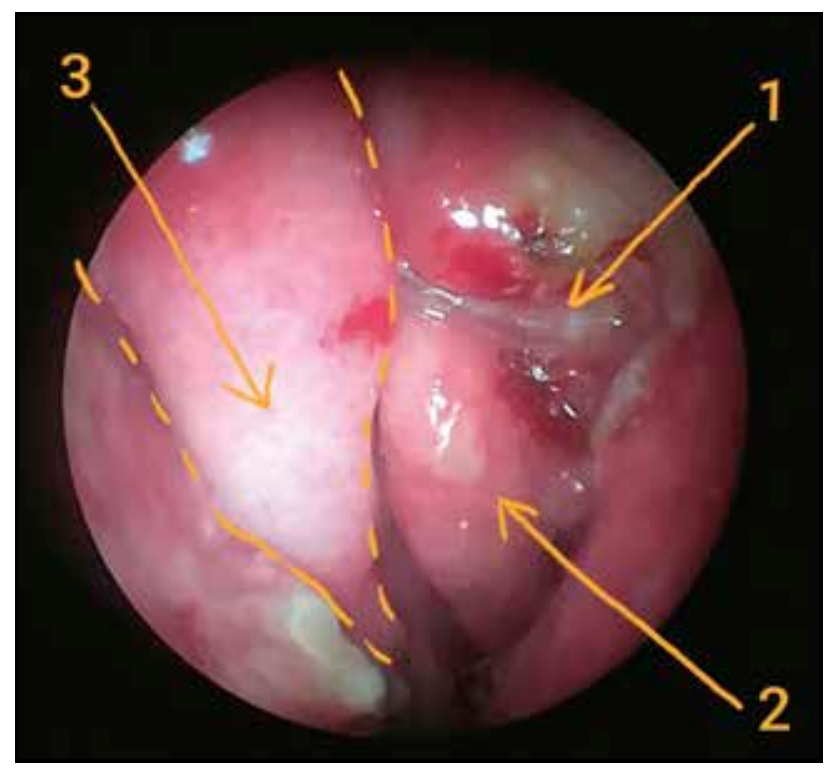

Figure 3 The "L-shaped" incision and the nasal septal mucosa flap that fixes the catheter as in a "sandwich" between the two septal mucosal membranes. 1. Catheter positioned in the lacrimal sac; 2. "L-shaped" incision of the nasal septal mucosa; 3. Middle nasal turbinate.

- from a technical point of view, it can be easily performed, it is not expensive, it strictly catheterizes the area of the residual lacrimal sac and of the nasolacrimal stoma without the risk of damaging the superior, inferior and common canaliculi.

- we can use catheters with a smaller or larger diameter depending on the necessity and the size of the nasolacrimal stoma.

- having a permeable lumen, the catheter favours secretion drainage. 
- in the first postoperative days, the ophthalmologist can perform local retrograde instillations through the catheter into the lacrimal sac.

\section{RESULTS}

Hospital discharge was made 3 days postoperatively; in all 3 cases patients had a favourable evolution, with the absence of epiphora and normal nasolacrimal drainage.

Removal of the catheter was easily made after a period between 14 and 25 days. The tunnel between the mucous membranes of the nasal septum is obstructed with a fibrin sealant, scarring being achieved in about 4-7 days.

The nasolacrimal stented orifice was maintained permeable, well defined, with normal tear discharge after the checkups performed at 1, 3 and 12 months. Fluorescein instillation was performed at each checkup, which revealed drainage at the level of permeable nasolacrimal stoma (Figure 4).

\section{DISCUSSIONS}

Catheterization of lacrimal pathways can be: bicanaliculonasal, monocanalicular, monocanaliculonasal ("MonoKa"), annular, autostatic.

In medical practice, a multitude of stents are used in various disorders of the lacrimal pathways, such as: stenosis or atresia of the lacrimal punctum, post-traumatically, post irradiation, in oncologic pathology, postsurgically (after DCR) ${ }^{1}$.

The stents are divided according to the anatomical part of the lacrimal system that must be stented or catheterized. Therefore, there is the possibility of catheterization of the two lacrimal canaliculi, the common canaliculus and the lacrimal sac, with the help of bicanalicular stents, such as: the Crawford stent, the Ritleng stent, the Bika stent, the self-retaining bicanalicular stent ${ }^{1-3}$.

In case of canalicular obstruction or laceration, monocanalicular stents may be used, which catheterizes a single canaliculus up to the lacrimal sac - the Monoka ${ }^{\mathrm{TM}}$ stent $(\mathrm{mono}=$ only one, $\mathrm{ka}=$ canaliculus $)$, Mini-monoka ${ }^{\mathrm{TM}}$, Monoka-Crawford, Masterka ${ }^{\mathrm{TM}}$ 2,4,5.

Over time, different types of material, such as organic, metallic or synthetic, have been used as a stent for the lacrimal punctum or for the lacrimal canalicular stenosis. The use of stents has been first described by Graue in 1932 (he used silver wire), followed by Henderson in 1950 (polyethylene) and Veir in 1962 (malleable metal rod) ${ }^{2,6,7}$. Since then, various materials such as silk, nylon or polypropylene have been frequently used. Over time, the design of stents has evolved, so

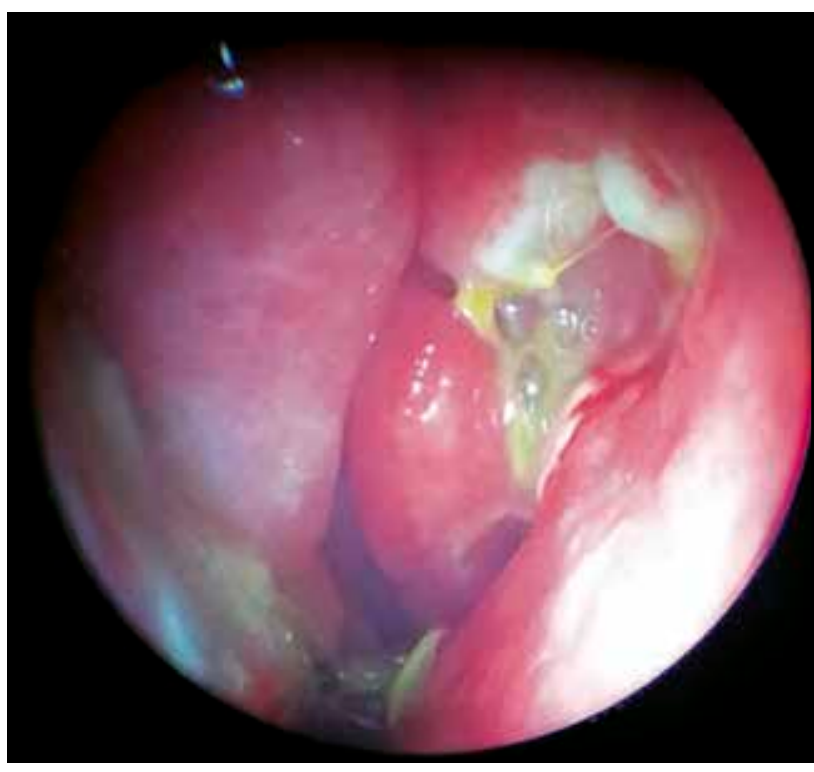

Figure 4 Verifying the permeability of the nasolacrimal stoma with fluorescein.

there is a lower degree of rejection by the human body, as well as a lower rate of local adverse reactions. The newer stents have improved the success of such surgical interventions and have reduced the frequency of complications.

There are certain features that a stent should fulfil: have an inert, flexible, smooth outer surface, so as not to cause mechanical damage to the surrounding soft tissues; to be cheap; to be easy to use. Medical silicone, introduced in 1968 by Keith, has most of these properties $^{8}$. Quickert \& Dryden in 1970 and Crawford, 1977, have improvised bicanalicular intubation devices and reported significant successes ${ }^{8-10}$. Based on these latest devices, Bruno Fayet (1989) and Ruban (1995) created the monocanalicular stent, and in 1998 Ritleng introduced the bicanalicular stenting device in case of congenital nasolacrimal duct obstruction ${ }^{11-13}$.

In terms of mechanism of action, a stent should be functional and anatomical ${ }^{14-16}$. By capillary action due to surface tension, tears can flow through the stent, thus keeping its permeability. The mechanical or anatomical effect of the stent is explained by dilatation of the area of stenosis or with irregularities, process that determines increase in the luminal diameter and increased lacrimal drainage.

Various situations where stent use is indicated are described in the literature. Canalicular and lacrimal punctum stenosis is a disorder in which the stent mechanically dilates the lacrimal punctum and the vertical canaliculi, restores normal tear flow and prevents restenosis. In case of laceration or canalicular trauma, the stents provide an internal "mechanical support" to the canalicular wall and the surrounding soft tissue and 
helps with the canalicular re-epithelialization, thus keeping the lumen functional.

Moreover, stent catheterization can be considered a viable option before dacryocystorhinostomy in case of congenital nasolacrimal duct obstruction ${ }^{14}$.

The stents can also be used after performing dacryocystorhinostomy to keep the ostium and internal canalicular structure open. Restenosis is the most common cause of failure in DCR surgery. Although there are pros and cons of this approach, it can be taken into account in case of reinterventions or reactivated chronic dacryocystitis.

There are also studies proving the usefulness of stents in the case of functional epiphora too; in these cases, they help with the drainage of tear secretion by keeping the lacrimal pathway open and improving symptoms ${ }^{11.17}$.

In cases with endoscopically operated dacryocystitis where the superior, inferior and common canaliculi are permeable, in order to be able to maintain the intranasal lacrimal sac open postsurgically, we considered it would be enough to locally mount a simple mentor (catheter). It would have the role of keeping this pathway open and calibrated, thus excluding the catheterization of the other components of the lacrimal pathways. The technical problems in this case would be the correct positioning in the intranasally open lacrimal sac, but also maintaining the mentor in this position as long as possible. In this regard, we have found simple and effective solutions that helped resolve the above-mentioned impediments.

\section{CONCLUSIONS}

Stenting can be done selectively in certain situations and at certain levels of the lacrimal pathways, with appropriate types of stent for each situation.

Most mono- and bicanalicular stents are expensive solutions that may involve certain intraoperative trauma during positioning, but also postsurgical inflammatory reactions of the superior lacrimal pathways.

I consider that the presented method to maintain the nasolacrimal stoma patent is simple to achieve, does not involve high costs and has no technical drawbacks. It has a low risk of secondary inflammatory reactions in the eye and the superior lacrimal pathways, as is often the case with bi- and monocanalicular stenting. At the same time, to keep the lacrimal pathway open to a certain caliber, one can opt for the use of catheters with diameters superior to those of bi-/monocanalicular catheters that are smaller than $1 \mathrm{~mm}$.

Conflict of interest: The authors have no conflict of interest.

Contribution of authors: All authors have equally contributed to this work.

\section{REFERENCES}

1. Ducasse A, Adenis JP, Fayet B, George JL, Ruban JM. Les voies lacrymales. Elsevier/Masson; 2006.

2. Fayet B, Assouline M, Bernard JA. Monocanalicular nasolacrimal duct intubation. Ophthalmology. 1998;105(10):1795-6. DOI: 10.1016/S01616420(98)91014-4

3. Ali MJ, Psaltis AJ, Ali MH, Wormald PJ. Endoscopic assessment of the dacryocystorhinostomy ostium after powered endoscopic surgery: behaviour beyond 4 weeks. Clin Exp Ophthalmol. 2014;43(2):152-5. DOI: 10.1111/ceo.12383. Epub 2014 Aug 12.

4. Kaufman LM, Guay-Bhatia LA. Monocanalicular intubation with Monoka tubes for the treatment of congenital nasolacrimal duct obstruction. Ophthalmology. 1998;105(2):336-41.

5. Goldstein S, Goldstein J, Katowitz JA. Comparison of monocanalicular stenting and balloon dacryoplasty in secondary treatment of congenital nasolacrimal duct obstruction after failed primary probing. Ophthalmic Plast Reconstr Surg. 2004;20(5):352-7.

6. Henderson JW. Management of strictures of the lacrimal canaliculi with polyethylene tubes. Arch Ophthalmol. 1950;44(2):198-203. DOI: 10.1001/archopht.1950.00910020203002.

7. Veirs ER. Malleable rods for immediate repair of the traumatically severed lacrimal canaliculus. Trans Am Acad Ophthalmol Otolaryngol. 1962;66:263-4.

8. Keith CG. Intubation of the lacrimal passages. Am J Ophthalmol. 1968;65(1):70-4.

9. Quickert MH, Dryden RM. Probes for intubation in lacrimal drainage. Trans Am Acad Ophthalmol Otolaryngol. 1970;74(2):431-3.

10. Crawford JS. Intubation of obstructions in the lacrimal system. Can J Ophthalmol. 1977;12(4):289-92.

11. Fayet B, Bernard JA, Pouliquen Y. Repair of recent canalicular wounds using a monocanalicular stent. Bull Soc Ophtalmol Fr. $1989 ; 89(6-7): 819-25$.

12. Ruban JM, Guigon B, Boyrivent V. Analysis of the efficacy of the large mono-canalicular intubation stent in the treatment of lacrimation caused by congenital obstruction of the lacrimal ducts in infants. J Fr Ophtalmol. 1995;18(5):377-83.

13. Pe MR, Langford JD, Linberg JV, Schwartz TL, Sondhi N. Ritleng intubation system for treatment of congenital nasolacrimal duct obstruction. Arch Ophthalmol. 1998;116(3):387-91.

14. Dave TV, Javed Ali M. Intubation in lacrimal surgery: Devices and Techniques. In: Javed Ali M (ed.). Principles and Practice of Lacrimal Surgery. India: Springer; 2015, p.289-301.

15. Repka MX, Chandler DL, Holmes JM, Hoover DL, Morse CL, Schloff S, Silbert DI, Tien DR; Pediatric Eye Disease Investigator Group. Balloon catheter dilation and nasolacrimal duct intubation for treatment of nasolacrimal duct obstruction after failed probing. Arch Ophthalmol. 2009;127(5):633-9. DOI: 10.1001/archophthalmol.2009.66.

16. Fayet B, Katowitz WR, Racy E, Ruban JM, Katowitz JA. Pushed monocanalicular intubation: an alternative stenting system for the management of congenital nasolacrimal duct obstructions. JAAPOS. 2012;16(5):468-72. DOI: 10.1016/j.jaapos.2012.07.003.

17. Shams PN, Chen PG, Wormald PJ, Sloan B, Wilcsek G, McNab A, et al. Management of functional epiphora in patients with an anatomically patent dacryocystorhinostomy. JAMA Ophthalmol. 2014;132(9):1127-32. DOI: 10.1001/jamaophthalmol.2014.1093. 